\title{
Correlação entre testes para avaliação da qualidade de sementes de girassol e emergência das plântulas em campo
}

\author{
Correlation between sunflower seeds quality evaluation tests and seedling emergence in field
}

\author{
Madelon Rodrigues Sá Braz ${ }^{\text {I }}$ Claudia Antonia Vieira Rossetto ${ }^{\text {II }}$
}

\section{RESUMO}

A capacidade do teste de germinação para estimar o potencial de emergência de plântulas no campo diminui à medida que as condições do ambiente são desfavoráveis. No entanto, diferentes testes de vigor têm sido utilizados para identificar os lotes de sementes que apresentam melhor desempenho nessas situações. O objetivo do trabalho foi correlacionar os resultados dos testes conduzidos no laboratório com a emergência das plântulas de girassol em campo. Para isso, cinco lotes de sementes de girassol da cultivar 'Embrapa 122 V2000' foram submetidos aos testes de germinação e vigor (primeira contagem, classificação de plântulas, teste de frio, condutividade elétrica, emergência de plântulas em areia $e$ em campo, índice de velocidade de emergência, envelhecimento acelerado e deterioração controlada). Em condições adversas, a emergência das plântulas de girassol em campo apresentou maior correlação com o vigor, avaliado pelos testes de envelhecimento acelerado, de deterioração controlada e de condutividade elétrica.

Palavras-chave: Helianthus annuus L., estabelecimento, potencial fisiológico.

\section{ABSTRACT}

The germination capacity test to estimate the potential of seedlings emergence in the field decreases when the environmental conditions are unfavorable. However, different vigour tests have been used to identify the seed lots that have better perform in these situations. The objective of this research was to correlate the results of tests conducted in the laboratory with the emergence of sunflower seedlings in the field. For this, five lots of seeds sunflower cultivar 'Embrapa 122 V2000' were submitted to the germination and vigour tests (first count, classification of seedlings, cold test, electrical conductivity, seedling emergence in sand and in the field, emergence speed index, accelerated aging and controlled deterioration). Under adverse conditions, the seed vigour evaluated by accelerated aging, controlled deterioration and electrical conductivity presented higher correlation with sunflower plant emergence in field.

Key words: Helianthus annuus L., establishment, physiological potential.

\section{INTRODUÇÃO}

O Brasil produziu 106,1 mil toneladas de sementes de girassol numa área de 75,4 mil hectares (CONAB, 2008), nos Estados de Goiás, São Paulo, Mato Grosso do Sul, Mato Grosso, Rio Grande do Sul e Paraná (LAZZAROTTO et al., 2005). Após a instituição do programa RioBiodiesel (Decreto Estadual n.37.927), tanto a região Norte (ANDRADE, 2006), quanto Sul do Estado do Rio de Janeiro (ORGADEM, 2008), têm sido favoráveis ao cultivo do girassol destinado ao uso na produção de biodiesel. No entanto, o girassol também tem sido utilizado para adubo verde e para silagem (AMABILE et al., 2002).

Para CASTRO \& FARIAS (2005), as condições ideais para a emergência do girassol são de temperatura do ar entre 20 e $25^{\circ} \mathrm{C}$ e de precipitação pluvial média de $0,6 \mathrm{~mm} \mathrm{dia}^{-1}$. No entanto, para ALBUQUERQUE \& CARVALHO (2003), a faixa de temperatura, sob a qual ocorre a porcentagem máxima de germinação, varia com a qualidade da semente e é geralmente menor em lotes de sementes deterioradas.

IPrograma de Pós-graduação em Fitotecnia, Universidade Federal Rural do Rio de Janeiro (UFRRJ), 23890-000, Seropédica, RJ, Brasil. E-mail: madelonsa@hotmail.com. Autor para correspondência.

IIDepartamento de Fitotecnia, Instituto de Agronomia, UFRRJ, Seropédica, RJ, Brasil. 
Para avaliar a qualidade das sementes, alguns testes vêm sendo recomendados. O teste de germinação tem sido utilizado para determinar a capacidade de as sementes produzirem plântulas normais, sob condições favoráveis de ambiente (CARVALHO \& NAKAGAWA, 2000), pois, de acordo com CARVALHO et al. (2006), este tem várias limitações para retratar o desempenho do lote em condições de campo. Assim, MARCOS FILHO (1999a) relata que, quando as condições de ambiente se desviam das mais adequadas, a avaliação do vigor é necessária para estimar o potencial de desempenho das sementes. Segundo o autor, os testes de vigor devem ser escolhidos de maneira a atender os objetivos específicos, completando as informações obtidas no teste de germinação. Em girassol, ANFINRUD \& SCHNEITER (1984) observaram que o teste de condutividade elétrica realizado sob o sistema individual, o teste de envelhecimento acelerado sob sistema tradicional a $41^{\circ} \mathrm{C}$, por 96 horas, e o teste de germinação a $10^{\circ} \mathrm{C}$ apresentaram maior correlação com o teste de emergência de plântulas em campo sob irrigação ou não que com o teste de germinação realizado no laboratório a $21^{\circ} \mathrm{C}$. Além disso, o teste de envelhecimento acelerado sob sistema tradicional a $42^{\circ} \mathrm{C}$, por 72 e 96 horas, realizado por ZELENER et al. (1990), e o teste de envelhecimento acelerado sob sistema tradicional a $42^{\circ} \mathrm{C}$, por 72 horas, realizado por ALBUQUERQUE et al. (2001), apresentaram correlação positiva com a emergência de plântulas em campo. Já para ALBUQUERQUE \& CARVALHO (2003) somente o teste de frio, realizado com ou sem solo, apresentou correlação significativa com a emergência das plântulas em campo sob diferentes condições de estresse (temperaturas de $35^{\circ} \mathrm{C}$ e de $15^{\circ} \mathrm{C}$, excesso e deficiência de água e semeadura a $7 \mathrm{~cm}$ de profundidade).

Dentro desse contexto, o objetivo neste trabalho foi correlacionar os resultados dos testes conduzidos no laboratório com a emergência das plântulas de girassol em campo.

\section{MATERIAL E MÉTODOS}

O experimento foi realizado na Universidade Federal Rural do Rio de Janeiro, em 2006. Foram utilizados cinco lotes de sementes (aquênios) de girassol (Helianthus annuus L.) da cultivar 'Embrapa 122 V2000’, safra 2006, fornecidos pela Embrapa Soja. Após o recebimento, os lotes foram acondicionados em embalagem de sacos de papel e mantidos em câmara seca a $17^{\circ} \mathrm{C}$ e $50 \%$ de umidade relativa do ar (UR), por dois meses. Os lotes apresentavam, em média, 7,0\% de água, massa média de 1000 sementes de 61,3g e 87\% das sementes retidas em peneira com crivo circular de diâmetro de 15/64”. O delineamento experimental adotado foi inteiramente casualizado, com quatro repetições, sendo os tratamentos representados pelos lotes.

Foi realizada a avaliação da qualidade fisiológica empregando os testes de germinação e de vigor, com quatro subamostras de 50 sementes. O teste de germinação foi conduzido em rolos de papel germitest mantidos sob temperaturas alternadas (20$30^{\circ} \mathrm{C}$ ), na ausência de luz. As avaliações foram realizadas aos quatro e 10 dias após a instalação dos testes (BRASIL, 1992). Em conjunto com esse teste, foi realizado o teste de primeira contagem, considerando a porcentagem de plântulas normais no $4^{\circ}$ dia após a instalação do teste (NAKAGAWA, 1999).

O teste de frio foi conduzido em substrato de papel germitest por sete dias sob temperatura de $10^{\circ} \mathrm{C}$, na ausência de luz (MURCIA et al., 2001). Posteriormente, os rolos foram mantidos a $20-30^{\circ} \mathrm{C}$. As avaliações foram realizadas aos quatro e 10 dias (BRASIL, 1992)

O teste de classificação das plântulas foi conduzido com 10 sementes em rolos de papel germitest mantidos sob temperaturas alternadas $\left(20-30^{\circ} \mathrm{C}\right)$, na ausência de luz. As avaliações foram realizadas aos quatro dias, considerando o comprimento (em mm) entre a extremidade da raiz primária e a região de inserção dos cotilédones das plântulas normais (NAKAGAWA, 1999). Além disso, após a remoção dos cotilédones, foi realizada a secagem a $80^{\circ} \mathrm{C}$, por 24 horas, para a determinação da massa da matéria seca das plântulas. Os resultados foram expressos em mg plântula ${ }^{-1}$ (NAKAGAWA, 1999).

O teste de envelhecimento acelerado foi conduzido com 320 sementes dispostas em camada única sobre tela de alumínio no interior de caixas plásticas tipo gerbox adaptado, onde foram adicionados $40 \mathrm{~mL}$ de solução saturada de $\mathrm{NaCl}$, visando a atingir 76\% de UR do ar (BRAZ et al., 2008). Posteriormente, essas caixas foram mantidas a $42^{\circ} \mathrm{C}$, por 96 horas. Após o período de exposição, foi determinado o teor de água das sementes, bem como foi feita a instalação do teste de germinação, considerando a porcentagem de plântulas normais aos quatro dias após a instalação.

Para o teste de deterioração controlada, primeiramente, foi realizado o ajuste do teor de água das sementes para $20 \%$, por meio do umedecimento pelo método de atmosfera úmida. Em seguida, as sementes foram acondicionadas em sacos de alumínio selados e mantidos a $42^{\circ} \mathrm{C}$, por 72 horas (BRAZ et al., 2008). Após o período de exposição, foi determinado o 
teor de água das sementes, bem como foi feita a instalação do teste de germinação, considerando a porcentagem de plântulas normais aos quatro dias após a instalação.

O teste de condutividade elétrica foi realizado após a remoção do pericarpo das sementes. Em seguida, as sementes foram previamente pesadas e imersas em $75 \mathrm{~mL}$ de água destilada e deionizada, durante 24 horas, a $25^{\circ} \mathrm{C}$ (BRAZ et al., 2008).

O teste de emergência de plântulas foi conduzido em caixas plásticas contendo areia lavada, esterilizada e umedecida com água destilada, visando a atingir $60 \%$ da capacidade de retenção. As caixas foram mantidas em condição ambiente, e as avaliações foram realizadas aos quatro e 10 dias após a instalação do teste (NAKAGAWA, 1999).

O teste de emergência de plântulas em campo foi conduzido em Planossolo. As avaliações foram realizadas diariamente por 21 dias. No final do período, foi realizada a avaliação da porcentagem de emergência das plântulas, e foi efetuado o cálculo do índice de velocidade de emergência (NAKAGAWA, 1999).

Os dados foram submetidos à análise de variância após terem sido realizados os testes de Lilliefors e de Cochran e Bartlett (RIBEIRO JUNIOR, 2001), para verificar a normalidade e homogeneidade dos erros. No entanto, não houve necessidade de transformação. As médias foram comparadas pelo teste Tukey, a 5\% de probabilidade. Também foi realizada a análise de correlação simples tipo Pearson entre os resultados dos testes de emergência de plântulas em campo e os testes conduzidos em laboratório, com base em RIBEIRO JUNIOR(2001).

\section{RESULTADOS E DISCUSSÃO}

Não foi observada diferença significativa de germinação entre os lotes de sementes de girassol
(Tabela 1) que apresentavam valores superiores ao do padrão para a comercialização (BRASIL, 2005). Quando as diferenças no potencial fisiológico entre os lotes de sementes são muito pequenas, provavelmente, estes não são possíveis de serem detectadas pelo teste de germinação. MARCOS FILHO (1999a) também comentou essa dificuldade na interpretação do teste de germinação. Além disso, quando se emprega o teste de germinação, este não permite detectar o progresso da deterioração das sementes, apenas indica a fase final do processo. Para MAEDA et al. (1985), o teste de germinação pode não discriminar lotes que apresentam diferentes níveis de deterioração porque a perda da capacidade germinativa é a última consequência do processo de deterioração das sementes.

Em relação aos testes de vigor, nos testes de comprimento e de massa de matéria seca das plântulas, não foi observada diferença significativa entre os lotes. Já pelo teste de primeira contagem, foi verificado que apenas o lote 1 apresentou valores inferiores que aos lotes 3, 4 e 5 . O lote 2 não foi estatisticamente diferente dos demais lotes. Todos esses três testes são baseados no desempenho de plântulas, podendo haver dificuldade na interpretação dos resultados, pois não há uma elaboração específica da metodologia para cada espécie e de valores de referência. No entanto, KRZYZANOWSKI et al. (1991) comentam que, para algumas espécies, esses testes já vêm sendo correntemente utilizados em pesquisa e em análises de rotina. Pelo teste de frio, o lote 5 foi superior aos demais lotes, que não diferiram entre si. Em girassol, ALBUQUERQUE \& CARVALHO (2003) também constataram que o teste de comprimento das plântulas não foi eficiente em classificar os lotes de sementes de girassol em diferentes níveis de vigor, e apenas o teste de frio permitiu a separação dos lotes.

Pelos testes de deterioração controlada e de envelhecimento acelerado sob sistema salino, foi

Tabela 1 - Dados médios de germinação (\%), de plântulas normais na primeira contagem (\%), de teste de frio (\%), de comprimento da plântula (mm plântula ${ }^{-1}$ ) e de massa de matéria seca de plântula (mg plântula ${ }^{-1}$ ), obtidos de cinco lotes de sementes de girassol.

\begin{tabular}{|c|c|c|c|c|c|}
\hline Lotes & $\begin{array}{c}\text { Germinação } \\
\text { (\%) }\end{array}$ & $\begin{array}{c}\text { Primeira contagem } \\
\text { (\%) }\end{array}$ & $\begin{array}{c}\text { Teste de frio } \\
\text { (\%) }\end{array}$ & $\begin{array}{l}\text { Comprimento de plântulas } \\
\left.\text { (mm plântula }{ }^{-1}\right)\end{array}$ & $\begin{array}{c}\text { Matéria seca de plântulas } \\
\text { (mg plântula }{ }^{-1} \text { ) }\end{array}$ \\
\hline 1 & $82 a^{1}$ & $60 \mathrm{~b}$ & $74 \mathrm{~b}$ & $278,3 a$ & $17 \mathrm{a}$ \\
\hline 2 & $82 \mathrm{a}$ & 63ab & $72 b$ & $253,1 \mathrm{a}$ & $17 \mathrm{a}$ \\
\hline 3 & $84 a$ & $70 a$ & $74 \mathrm{~b}$ & $265,1 \mathrm{a}$ & $15 a$ \\
\hline 4 & $82 \mathrm{a}$ & $70 \mathrm{a}$ & $74 \mathrm{~b}$ & $276,2 a$ & $14 a$ \\
\hline 5 & $87 a$ & $71 \mathrm{a}$ & $80 a$ & $237,0 \mathrm{a}$ & $14 a$ \\
\hline $\mathrm{CV}(\%)$ & 4,54 & 4,59 & 6,23 & 9,25 & 10,80 \\
\hline DMS & 8,56 & 6,96 & 10,51 & 5,46 & 5,46 \\
\hline
\end{tabular}

${ }^{1}$ Médias não ligadas por mesma letra diferem pelo teste de Tukey, a 5\%.

Ciência Rural, v.39, n.7, out, 2009. 
constatado que os lotes 2 e 5 apresentaram desempenho superior aos lotes 1 e 4 , que, pelo teste de deterioração controlada, não diferiram do lote 3 , mas apresentaram o menor desempenho no teste de envelhecimento acelerado (Tabela 2). Assim, esses testes permitiram identificar as diferenças apenas entre os lotes de vigor alto e baixo, não revelando claramente as diferenças entre os lotes de médio vigor. Além disso, foi verificado que o teor de água das sementes dos cinco lotes, após a realização dos testes, foi semelhante entre si. Esse resultado pode se um dos principais indicadores da uniformização das condições do teste, com base nas informações de MARCOS FILHO (1999b). Também em girassol, BRAZ et al. (2008) constataram que os testes de envelhecimento acelerado e de deterioração controlada foram eficientes em classificar os lotes em diferentes níveis de vigor.

Pelo teste de condutividade elétrica, os lotes 1,2 e 5 são classificados como de maior vigor que o lote 4, por apresentar os menores valores de condutividade elétrica na solução de embebição, devido ao menor valor de lixiviação de solutos (Tabela 3). Além disso, esse teste indicou o lote 4 como de menor vigor que os lotes 1 e 5. ALBUQUERQUE et al. (2001) também constataram que o teste de condutividade elétrica realizado pelo sistema de massa permitiu classificar os lotes de sementes de girassol em diferentes níveis de vigor. No entanto, para MURCIA et al. (2001), a classificação dos lotes em diferentes níveis de vigor somente foi verificada quando o teste de condutividade foi realizado pelo sistema individual.

Pelos testes de emergência de plântulas em areia e de índice de velocidade de emergência (IVE), não houve diferença significativa entre os lotes, assim como também foi constatado pelo teste de germinação e de comprimento e massa de matéria seca das plântulas
(Tabela 1). Já pelo teste de emergência de plântulas em campo, foi possível identificar a inferioridade do lote 4 (Tabela 3), ratificando os resultados de condutividade elétrica.

Os testes de germinação e de primeira contagem de germinação (Tabela 4) não apresentaram correlação significativa com o teste de emergência de plântulas em campo, provavelmente, devido às condições de restrição hídrica e temperatura média máxima de $29,9^{\circ} \mathrm{C}$ entre o $9^{\circ}$ e $16^{\circ}$ dia após a instalação do teste. Para CASTRO \& FARIAS (2005), as condições ideais para o estabelecimento das plantas é de temperatura do ar entre 20 e $25^{\circ} \mathrm{C}$ e precipitação pluvial de $0,6 \mathrm{~mm} \mathrm{dia}^{-1}$. Já para TOMAZELA et al. (2008), a germinação das sementes de girassol cai bruscamente sob temperaturas acima de $25^{\circ} \mathrm{C}$. Assim, esses resultados de redução da emergência sob deficiência hídrica (-1,1MPa) também foram constatados por SOMERS et al. (1983) e HELMS et al. (1997).

Não foi constatada correlação significativa entre a emergência de plântulas em campo e os testes de massa de matéria seca e comprimento das plântulas, emergência de plântulas em areia, índice de velocidade de emergência e de teste de frio (Tabela 4).

O teste de condutividade elétrica apresentou correlação negativa e significativa com o teste de emergência de plântulas em campo. PARVATHAMMA et al. (1991) somente verificaram alta correlação entre o teste de condutividade elétrica (usando o sistema de massa) e a emergência de plântulas em campo sob condições favoráveis ao desenvolvimento das plântulas de girassol. Também em girassol, ANFINRUD \& SCHNEITER (1984) verificaram correlação significativa entre o teste de condutividade elétrica pelo sistema individual e o de emergência de plântulas, quando a emergência ocorreu em ambiente com ou sem irrigação.

Tabela 2 - Dados médios de teor de água e de plântulas normais (\%), obtidos de cinco lotes de sementes de girassol após os testes de deterioração controlada e de envelhecimento acelerado.

\begin{tabular}{|c|c|c|c|c|}
\hline \multirow{2}{*}{ Lotes } & \multicolumn{2}{|c|}{-------------------Deterioração controlada----------------- } & \multicolumn{2}{|c|}{------------------Envelhecimento acelerado-------------- } \\
\hline & Teor de água & Plântulas normais & Teor de água & Plântulas normais \\
\hline 1 & $20,5 a^{1}$ & $47 \mathrm{c}$ & $8,3 a$ & 50c \\
\hline 2 & $20,7 \mathrm{a}$ & $59 a b$ & $7,8 \mathrm{a}$ & $62 \mathrm{ab}$ \\
\hline 3 & $20,4 a$ & $51 \mathrm{bc}$ & $7,8 \mathrm{a}$ & $60 \mathrm{~b}$ \\
\hline 4 & 19,9a & 49c & $7,8 \mathrm{a}$ & $50 \mathrm{c}$ \\
\hline 5 & 20,1a & $66 a$ & $7,8 \mathrm{a}$ & $70 \mathrm{a}$ \\
\hline $\mathrm{CV}(\%)$ & 2,91 & 8,44 & 2,81 & 6,67 \\
\hline DMS & 1,33 & 10,38 & 0,50 & 8,79 \\
\hline
\end{tabular}

${ }^{1}$ Médias não ligadas por mesma letra diferem pelo teste de Tukey, a 5\%. 
Tabela 3 - Dados médios de condutividade elétrica $(\mu \mathrm{S} / \mathrm{cm} / \mathrm{g})$, de emergência de plântulas em areia e em campo (\%) e de índice de velocidade de emergência de plântulas em campo (IVE), obtidos de cinco lotes de sementes de girassol.

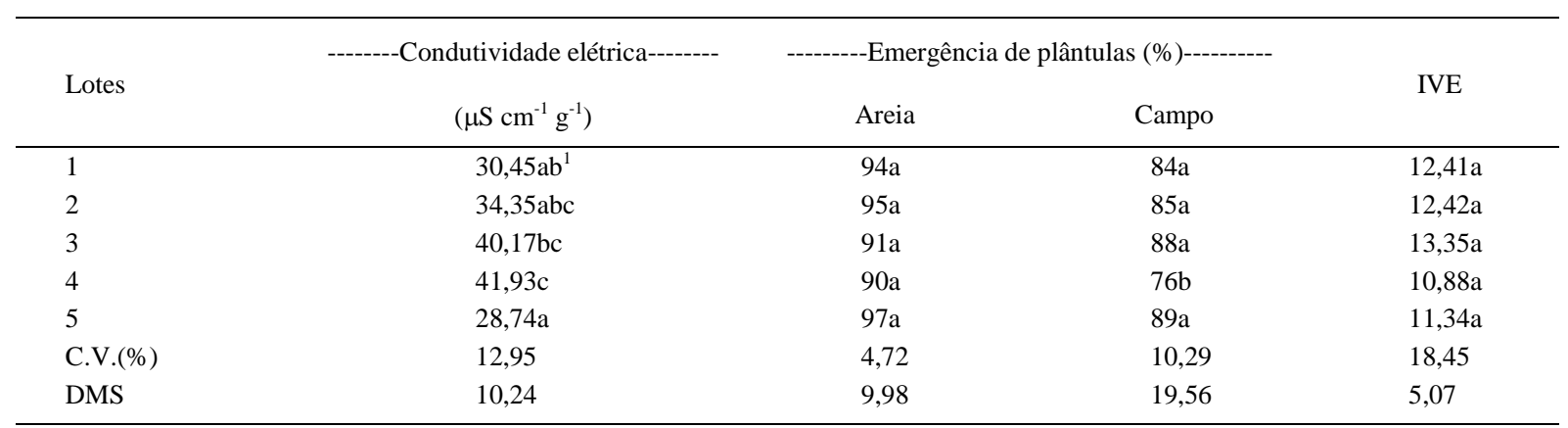

${ }^{1}$ Médias não ligadas por mesma letra diferem pelo teste de Tukey, a 5\%.

Houve também correlação significativa positiva entre o teste de emergência das plântulas em campo com o teste de envelhecimento acelerado e o de deterioração controlada. Esses resultados, que mostram a tendência de variação comparáveis entre si, servem para contribuir para a obtenção de informações que visem à tomada de decisões quanto à seleção dos lotes. Além disso, esses resultados devem ser interpretados em conjunto com os obtidos com a utilização de vários outros testes de vigor. Em girassol, também ZELENER et al. (1990) verificaram que o teste de envelhecimento acelerado sob sistema tradicional a $42^{\circ} \mathrm{C}$, por 72 e 96 horas, apresentou correlação positiva com a emergência

Tabela 4 - Coeficiente de correlação de Pearson (r) entre os resultados dos testes de germinação, de primeira contagem, de massa de matéria seca de plântula, de comprimento de plântula, de teste de frio, de emergência de plântulas em areia, de índice de velocidade de emergência (IVE), de condutividade elétrica, de deterioração controlada e de envelhecimento acelerado, com o teste de emergência de plântulas de girassol em campo.

\begin{tabular}{lc}
\hline Testes de laboratório & $\begin{array}{c}\text { Emergência de plântulas } \\
\text { em campo }\end{array}$ \\
\hline Germinação & $0,110^{\text {n.s. }}$ \\
Primeira contagem & $-0,237^{\text {n.s. }}$ \\
Massa de matéria seca de plântula & $0,120^{\text {n.s. }}$ \\
Comprimento de plântula & $-0,223^{\text {n.s. }}$ \\
Teste de frio & $-0,230^{\text {n.s. }}$ \\
Emergência de plântula em areia & $0,414^{\text {n.s. }}$ \\
IVE & $0,708^{\text {n.s. }}$ \\
Condutividade elétrica & $-0,467^{*}$ \\
Deterioração controlada & $0,546^{* *}$ \\
Envelhecimento acelerado & $0,516^{* *}$ \\
\hline
\end{tabular}

n.s não significativo, ${ }^{* *}$ significativo a $1 \%$ e * significativo a $5 \%$ de probabilidade. no campo. Já para ANFINRUD \& SCHNEITER (1984), o teste de emergência de plântulas em campo para ambiente com ou sem irrigação se correlaciona significativamente com o teste de envelhecimento acelerado sob sistema tradicional a $41^{\circ} \mathrm{C}$ e por 96 horas.

\section{CONCLUSÕES}

Em condições adversas, a emergência das plântulas de girassol em campo apresentou maior correlação com o vigor, avaliado pelos testes de envelhecimento acelerado, de deterioração controlada e de condutividade elétrica.

\section{AGRADECIMENTOS}

Os autores agradecem ao Conselho Nacional de Desenvolvimento Científico e Tecnológico (CNPq), pela concessão das bolsas, e à Embrapa Soja, pela doação dos lotes de aquênios de girassol.

\section{REFERÊNCIAS}

ANDRADE, W.E. de B. Viabilidade técnica do cultivo de oleaginosas no Norte Fluminense. A experiência da PesagroRio. Campos dos Goytacazes, RJ: Pesagro, 2006. 47p.

ANFINRUD, N.M.; SCHNEITER, A.A. Relationship of sunflower germination and vigor tests to field performance. Crop Science, Madison, v.24, p.341-344, 1984.

ALBUQUERQUE, M.C.de F. et al. Testes de condutividade elétrica e de lixiviação de potássio na avaliação da qualidade fisiológica de sementes de girassol. Revista Brasileira de Sementes, Brasília, v.23, n.1, p.1-8, 2001.

ALBUQUERQUE, M.C.de F.; CARVALHO, N.M. Effects of the environmental stress on the emergence of sunflower (Helianthus annus L.), soybean (Glycine max L. Merril) and maize (Zea mays L.) seeds with different levels of vigor. Seed Science and Technology, Zurich, v.31, p.465-479, 2003.

Ciência Rural, v.39, n.7, out, 2009. 
AMABILE, R.F. et al. Girassol como alternativa para o sistema de produção do cerrado. Planaltina, DF: EMBRAPA, 2002, 2p. (Circular Técnica).

BRASIL. Ministério da Agricultura e Reforma Agrária. Regras para análise de sementes. Brasília: SNDA/DNDV/CLAV, 1992. 365p.

BRASIL. Instrução Normativa n.25, de 16 de dezembro de 2005. Diário Oficial da República Federativa do Brasil, Poder Executivo, Brasília, DF, 16 dez. 2005

BRAZ, M.R.S. et al. Testes de envelhecimento acelerado e deterioração controlada na avaliação do vigor de aquênios de girassol. Ciência Rural, Santa Maria, v.38, n.7, p.18571863, 2008. Disponível em: <http://www.scielo.br/ scielo.php ? script=s ci_art text \& pi d = S 0103 4782008000700009\&lng=pt\&nrm=iso>. Acesso em 12 mai. 2009. doi: 10.1590/S0103-84782008000700009.

CARVALHO, N.M. de.; NAKAGAWA, J. Sementes: ciência, tecnologia e produção. 4.ed. Jaboticabal: Funep, 2000. 588p.

CARVALHO, M.L.M. de, et. al. Controle e qualidade na produção de sementes. Informe agropecuário, Belo Horizonte, v.27, n.232, p.52-58, 2006.

CASTRO, C. de; FARIAS, J.R.B. Ecofisiologia do girassol. In: LEITE, R.M.V.B de C. et al. Girassol no Brasil. Londrina: Embrapa soja, 2005. p.163-218.

CONAB. Acompanhamento da safra brasileira: grãos: sexto levantamento, março 2008. Brasília: Companhia Nacional de Desenvolvimento, 2008. 30p.

HELMS, T.C. et al. Corn, sunflower, and soybean emergence influenced by soil temperature and soil water content. Agronomy Journal, Madison, v.89, n.1, p.59-63, 1997.

KRZYZANOWSKI, F.C. et al. Relato dos testes de vigor disponíveis para as grandes culturas. Informativo Abrates, Brasília, v.1, n.2, p.15-59, 1991

LAZZAROTTO, J.J. et al. Agronegócio do girassol no mundo e no Brasil. In: LEITE, R.M.V.B. de C. et al. Girassol no Brasil. Londrina: Embrapa Soja, 2005. p.15-42.
MAEDA, J.A. et al. Sementes de girassol: observações preliminares sobre o teste de envelhecimento rápido. Bragantia, Campinas, v.44, n.1, p.417-420, 1985. Disponível em: <http:/ /www.scielo.br/scielo.php?script=sci_abstract \&pid=S000687051985000100037\&lng=pt\&nrm=iso\&tlng=pt $>$. Acesso em: 12 mai. 2009. doi: 10.1590/S0006-87051985000100037.

MARCOS FILHO, J. Testes de vigor: Importância e utilização. In: KRZYZANOWSKI, F.C. et al. Vigor de sementes: conceitos e testes. Londrina: ABRATES, 1999a. p.1-21.

MARCOS FILHO, J. Testes de envelhecimento acelerado. In: KRZYZANOWSKI, F.C. et al. Vigor de sementes: conceitos e testes. Londrina: ABRATES, 1999b. p.3.1-3.21.

MURCIA, M. et al. Vigor de semillas y emergência a campo de girassol (Helianthus annus L.) em siembras anticipadas em el sudeste de la província de Buenos Aires (Argentina). Revista Brasileira de Sementes, Brasília, v.23, n.2, p.263-267, 2001.

NAKAGAWA, J. Testes de vigor baseados na avaliação das plântulas. In: KRZYZANOWSKI, F.C. et al. Vigor de sementes: conceitos e testes. Londrina: ABRATES, 1999. p.2.1-2.21.

ORGADEM. Biodiesel em Queimados. Rio de Janeiro, 19 abr. 2006. Disponível em: <http://www.orgadem.org.br/ biodieselqueimados.htm>. On line. Acesso em: 22 abr. 2008.

PARVATHAMMA, S. et al. Evaluation of seed vigour in sorghum and sunflower. Advances in Plant Science, India, v.4, n.1, p.35-42, 1991

RIBEIRO JÚNIOR, J.I. Análises estatísticas no SAEG. 19.ed. Viçosa: UFV, 2001. 301p.

SOMERS, D.A. et al. Sunflower germination under simulated drought stress. Agronomy Journal, Madison, v.75, n.3, p.570572, 1983.

TOMAZELA, A.L. et al. Girassol. In: CASTRO, P.R.C. et al. Manual de fisiologia vegetal: fisiologia dos cultivos. Piracicaba: Agronômica Ceres, 2008. 92-112p.

ZELENER, N. et al. Prueba de invejecimiento acelerado en girasol (Helianthus annuus L.) e interpretación de sus resultados. In: SEMINARIO PANAMERICANO DE SEMILLAS, 13.,1990, Guatemala. Acta... Guatemala:FELAS, 1990. n.p. 